\title{
An in-plane thermal unimorph using confined polymers
}

\author{
G K Lau ${ }^{1}$, T Chu Duc ${ }^{2}$, J F L Goosen ${ }^{1}$, P M Sarro ${ }^{2}$ and \\ F van Keulen ${ }^{1}$ \\ ${ }^{1}$ PME, Faculty of 3ME, Delft University of Technology, Mekelweg 2, 2628 CD Delft, \\ The Netherlands \\ ${ }^{2}$ ECTM, DIMES, Delft University of Technology, Feldmannweg 17, 2600 GB Delft, \\ The Netherlands \\ E-mail: g.lau@3me.tudelft.nl
}

Received 19 December 2006, in final form 16 February 2007

Published 2 July 2007

Online at stacks.iop.org/JMM/17/S174

\begin{abstract}
This paper presents the design, simulation and characterization of a new type of in-plane thermal unimorph, which utilizes composite SU-8/silicon microstructures. The unimorph consists of a silicon skeleton and SU-8 photoresist, which encapsulates the silicon skeleton. The silicon skeleton is asymmetric in shape, consisting of a straight segment and a meandering segment. Gaps and surrounds of the skeleton are filled with the SU-8 polymer. Bonds between the polymer filling and the sidewalls of the silicon microstructure enhance thermal expansion and stiffness of the polymer in a transverse direction. Therefore, this unimorph design delivers excellent actuation performance. The composite actuator bends laterally when electro-thermally activated. A $530 \mu \mathrm{m}$ long, $90 \mu \mathrm{m}$ wide and $50 \mu \mathrm{m}$ thick micro-machined device achieves a maximum lateral displacement of $25 \mu \mathrm{m}$ at a $1.75 \mathrm{~V}$ driving voltage and at $17.8 \mathrm{~mW}$ input power, at an average temperature below $200{ }^{\circ} \mathrm{C}$. It has a simulated lateral stiffness of $1.2 \mathrm{kN} \mathrm{m}^{-1}$. At $1.75 \mathrm{~V}$, it is estimated to produce a $30 \mathrm{mN}$ lateral blocked force that is high compared to other micro-actuators.

(Some figures in this article are in colour only in the electronic version)
\end{abstract}

\section{Introduction}

Bimetals are laminates of two metals with different coefficients of thermal expansion (CTE). The laminate is constructed by bonding the two metal layers together. When heated, bimetals deflect perpendicular to the bonding surface. They are also known as thermal bimorphs or unimorphs in the literature. The concept of bimetal actuation can be extended to multilayer design or multi-morph design using non-metallic materials or semiconductor materials. The laminate design has been miniaturized for a wide range of applications, where a large actuation range and low driving voltages are required. For example, Rietmueller and Benecke [1] fabricated bimorph actuators consisting of epitaxial silicon and gold film activated by a polysilicon heater; Ataka et al [2] demonstrate large outof-plane bending using tri-layers of high-CTE polyimide, a metallic heating film $(\mathrm{Ni} / \mathrm{Au} / \mathrm{Cr})$ and low-CTE polyimide.
Despite their successful application, the laminate design of electro-thermal micro-actuators is mostly limited to produce motion perpendicular to the wafer plane. This is because they are made of planar layers on the wafer. If in-plane motion is required, construction of the laminate design has to be rotated by $90^{\circ}$, becoming perpendicular to the wafer plane. This is difficult to make using micro-fabrication. Sehr et al [3] have demonstrated such a rotated design, by depositing aluminum (Al) on a sidewall of a silicon vertical beam. The sidewall deposition is done at a shallow incidence angle. Successful deposition requires that the sidewall of the vertical beam is free from the shadow of neighboring structures. As a consequence, the vertical laminate could not be packed closely to other microstructures. This makes the design and fabrication of vertical laminates more complicated than those of planar laminates. 


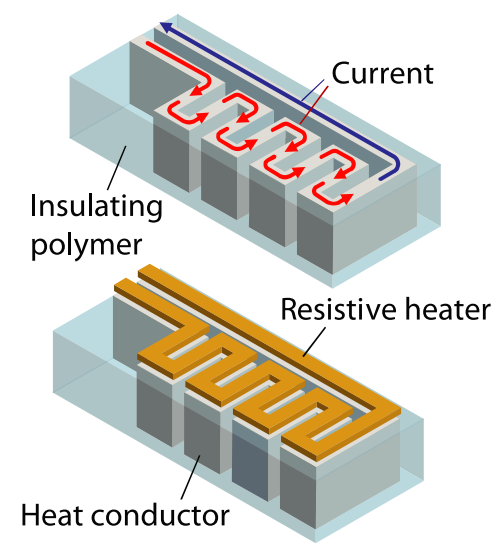

Figure 1. Schematic drawings showing the conceptual design of an asymmetric actuator using multiple materials: (top) electric current flow path on the top of a meandering silicon microstructure; (bottom) heater on the top of meandering silicon microstructure.

Owing to the difficulties involved, the vertical thermal bimorph using two materials is not adopted widely for in-plane actuation. Instead, mono-material asymmetric designs are more widely adopted as in-plane thermal actuators. One type of mono-material design is an asymmetric design, consisting of a wide arm and a narrow arm which are parallel to each other and joined at their tips in a $U$ shape. The asymmetric designs exploit differential heating of the asymmetric flexures to produce a lateral bending. Guckel et al [4] first presented such an asymmetric design and fabricated it using nickel electroplating. Comtois and Bright [5], Pan and Hsu [6] later demonstrated them using surface micromachining of polysilicon. Recently, Nguyen et al [7], Chronis and Lee [8] demonstrated designs using SU-8 epoxy and a surface metallic heating film.

Performance of these asymmetric thermal actuators depends to a large extent on expansion materials [4-8]. Materials of high CTE, such as polymers, are preferred to produce large displacements at low operating temperatures [7, 8]. However, polymers have low elastic moduli. As a consequence, they cannot produce as much actuation force as silicon and metals. In addition, they are poor electrical and thermal conductors. To overcome the limitations of polymers while tapping their benefits, a search for alternative designs is needed. Instead of using a single material, as for the asymmetric actuators, we explore the use of multiple materials to achieve effective thermal actuation for in-plane applications.
In addition, a fabrication method is developed to realize the multi-material design.

\section{Design concept}

The proposed design acts as an in-plane thermal unimorph. It bends laterally when activated. The unimorph actuator has an asymmetric geometry and consists of multiple materials (figure 1). It primarily consists of a silicon 'skeleton' and a polymeric expansion material, which encapsulates the silicon 'skeleton'. The silicon 'skeleton' is a high-aspect-ratio microstructure with deep trenches. The silicon skeleton is asymmetric in shape, consisting primarily of a long straight segment and a meandering segment (see figure 2). The straight segment is connected to the meandering segment at the front tip, where an apex is defined. The top of the silicon skeleton is coated with a thin film heater. The polymeric material fills the gaps and surrounds the silicon microstructure. It is expected to have perfect bonds with the sidewalls of the silicon microstructure.

Before discussing the thermally induced motion, a convention of direction is defined in this paper with reference to figure $2(b)$. The longitudinal or transverse direction is along the $y$-axis; the lateral direction is along the $x$-axis while the normal direction is along the $z$-axis. Both $x$ - and $y$-axes are parallel to the wafer plane while the $z$-axis is normal to the wafer plane. When activated by resistive heating, the polymeric filling expands in volume and is capable of opening the gaps between the meandering silicon skeleton. The polymeric expansion is predominantly in the longitudinal direction (see figure 2(b)) and it is higher than that for the straight silicon beam. The difference in thermal expansion pushes the straight beam through a cross beam, and it is converted into a lateral bending about the $z$-axis.

The polymer encapsulant, together with the embedded meandering silicon segment, resembles a stacked configuration of polymer and silicon layers. It is expected to manifest similar properties to a polymer layer filled in the gap between two silicon layers. The actuation capability of the bonded polymer is enhanced in several aspects. First, the heat transfer to and from the polymer is substantially improved by the embedded silicon. Second, volumetric expansion of the bonded polymer is concentrated in a transverse direction along the $y$-axis owing to the constraints of the bonded surfaces in the lateral direction along the $x$-axis. This results in a higher apparent linear CTE in the transverse direction, as compared
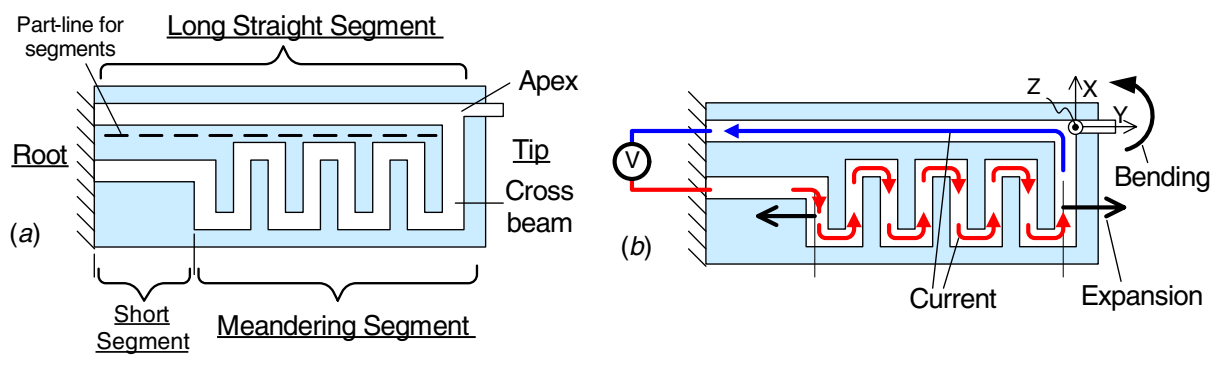

Figure 2. Top layout of the multi-material asymmetric actuator: $(a)$ definition and nomenclature of segments; $(b)$ induced current and actuation directions under the driving voltage. 


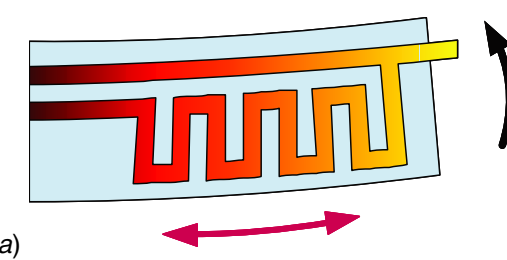

(b)

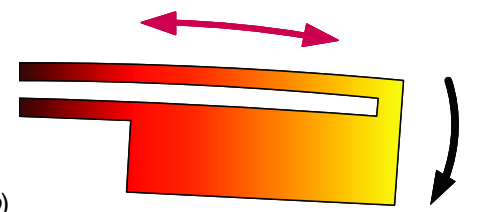

Figure 3. Actuation principles based on $(a)$ heating of the layered-stack design with asymmetric geometry; $(b)$ differential heating of single-material asymmetric actuator.

to a free polymer. On the other hand, there remains little lateral expansion, which appears as slight bulging, at the free edges of the bonded polymer. Third, the bonded polymer is reinforced by the silicon layers, resulting in a larger apparent stiffness in the transverse direction [9].

Silicon is favored here over metals as a heat conductor because silicon micromachining (using deep reactive ion etching) can readily form deep trenches, of high aspect ratio, for polymer filling. In the present design, photo-patternable epoxy, i.e. SU-8 photoresist, is adopted as an expansion polymer because it is easy to process and it possesses high CTE and good thermal stability, as compared to other thermal expandable materials.

The operating principle of the present design is based on differential thermal expansion between the straight segment and the meandering segment (see figure $3(a)$ ). Thus, it is very similar to the actuation principle of vertical bimetals [3]. Even at a uniform temperature rise, the present actuator design will bend laterally. The bending direction is towards the silicon straight beam when the actuator is heated. However, the actuation direction reverses if the actuator undergoes a temperature drop below the initial temperature for the original position. Such thermal-mechanical response to uniform heating may possibly be an advantage or a disadvantage depending on applications.

The actuation principle for the present composite actuator is different from that for the single-material asymmetric actuators (see figure $3(b)$ ). The single-material design bends under differential heating, which induces a high temperature in a slender arm but a relatively low temperature in another arm of larger width. The hot slender arm expands more than the cool arm. This principle causes a bending direction opposite to that of the newly proposed composite actuator, whose slender arm remains cool relative to the larger width composite stack.

\section{Finite element modeling}

The proposed actuator design comprises three materials: silicon, aluminum and SU-8 epoxy. It is a composite structure with a complex geometry. When activated thermally, it undergoes complex deformations, which cannot be described using a simple analytical method. Here, finite element (FE) modeling is used to evaluate the performance of the new thermal actuator. The finite element software package ANSYS is used for the modeling. Two 3D models were built for two separate analyses. A model of coupled-field elements (SOLID5) is used to simulate the electric, thermal and mechanical fields under steady-state resistive heating. In addition, a 3D model of structural elements (SOLID45) at room temperature is used for estimating stiffness of the actuator under constant-force loading at the tip.
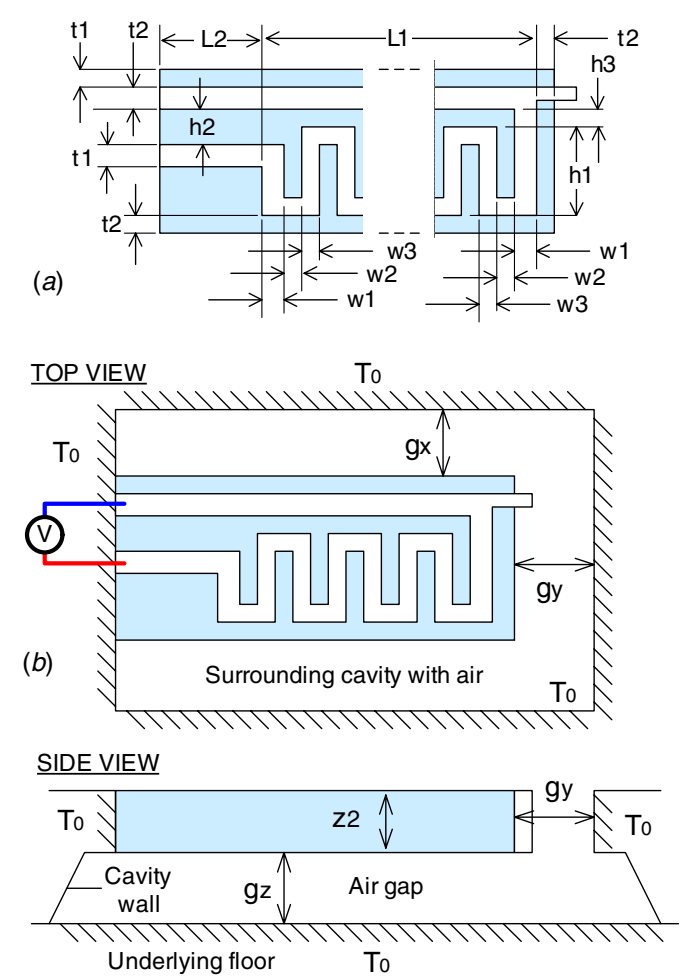

Figure 4. Dimensions and boundary conditions: $(a)$ dimensions of top layout as given in table 2; $(b)$ top and side views of cavity surrounding the actuator with temperatures indicated on the boundary.

\section{Boundary conditions and geometry}

Figure 4 shows the configuration of the actuator modeled and the boundary conditions imposed. The actuator model resembles an over-hanging cantilever. The actuator is clamped at the root. The remaining parts of the actuator are free to move. The root temperature is fixed at constant room temperature, i.e. $25^{\circ} \mathrm{C}$. The air in the cavity surrounding or beneath the actuator is not modeled in this context, but its effect on heat transfer either by conduction or convection can be accounted for using an effective heat transfer coefficient. The actuator is loaded either electro-thermally or mechanically. In the coupled electro-thermo-mechanical analysis, an electric potential is applied across the aluminum heater. In the mechanical analysis to estimate stiffness, three orthogonal loads are applied separately at the apex of the asymmetric composite actuator (see figure 2).

The asymmetric actuator has geometric dimensions listed in table 1 . The actuator consists of a $0.675 \mu \mathrm{m}$ thick Al film, a $50 \mu \mathrm{m}$ thick Si microstructure and polymer encapsulant. 
Table 1. Dimensions used for geometry modeling.

\begin{tabular}{ll}
\hline Geometry and dimensions & Values $(\mu \mathrm{m})$ \\
\hline $\begin{array}{l}\text { Length of a long beam minus offset, } L 1 \\
\text { Length of a short offsetting beam, } L 2\end{array}$ & 500 \\
Thickness of cross beams, $w 1$ & 5 \\
Spacing of a horseshoe bend, $w 2$ & 3 \\
$\begin{array}{l}\text { Thickness of a horseshoe bend, } w 3 \\
\text { Envelope width of the meandering } \\
\text { structures, } h 1\end{array}$ & 3 \\
$\begin{array}{l}\text { Spacing between the long beam and } \\
\text { the short beam, } h 2\end{array}$ & 15 \\
$\begin{array}{l}\text { Spacing between the long beam and } \\
\text { meandering segment, } h 3\end{array}$ & 5 \\
$\begin{array}{l}\text { Thickness of the long beam and the } \\
\text { short beam, } t 1\end{array}$ & 5 \\
$\begin{array}{l}\text { Width of the surrounding rim of } \\
\text { polymer, } t 2\end{array}$ & 8 \\
$\begin{array}{l}\text { Vertical thickness of aluminum } \\
\text { layer, } z 1 \text { (not shown) }\end{array}$ & 0.675 \\
$\begin{array}{l}\text { Vertical thickness of silicon layer, } z 2 \\
\text { Air gap on the side of the actuator, } g_{x}\end{array}$ & 50 \\
$\begin{array}{l}\text { Air gap in front of the actuator, } g_{y} \\
\text { Air gap beneath the actuator, } g_{z}\end{array}$ & 300 \\
\hline
\end{tabular}

Figure 4(a) shows the top layout of the polymer and the aluminum heater. Beneath the heater is the silicon microstructure, which has an identical layout to the heater. The heater layout consists of three segments: a long straight segment connects to a meandering segment, which is followed by a short straight segment (see also figure $2(a)$ ). The long straight segment is parallel to the short straight segment. The long straight segment is $5 \mu \mathrm{m}$ wide and $530 \mu \mathrm{m}$ long. The meandering segment is $3 \mu \mathrm{m}$ wide and it spans over $500 \mu \mathrm{m}$ $(L 1)$ while the short offsetting segment spans $30 \mu \mathrm{m}(L 2)$. The meandering segment consists of many horseshoe bends, which are $78 \mu \mathrm{m}$ long $(h 1)$ and $3 \mu \mathrm{m}$ wide $(w 3)$ with a $3 \mu \mathrm{m}$ spacing $(w 2)$. The meandering segment connects to the other two segments, through $5 \mu \mathrm{m}$ thick $(w 1)$ cross beams.

\section{Material properties}

As a preliminary study, the present modeling assumes that material properties, such as Young's modulus, thermal expansion coefficient and thermal conductivity, are constant and temperature independent $[6,10]$. However, electrical resistivity is assumed to be temperature dependent at a constant temperature coefficient of resistivity (TCR). SU-8 epoxy is very sensitive to process conditions, methods of testing and geometry of the test sample. Consequently, SU-8 is reported to have a considerable variation in measured properties [11-14]. In the present design, the SU-8 layers are predominantly confined in the trenches between neighboring silicon layers. The SU-8 layers in this configuration are very similar to a test sample confined in a closed cylinder of a pressure-volume-temperature (PVT) apparatus [11, 12]. They are therefore expected to exhibit bulk properties, measured from the PVT apparatus. Based on this, we adopted the comprehensive SU-8 properties reported by Feng and Farris $[11,12]$. In the present modeling, the linear CTE is taken as one third of the bulk volumetric expansion coefficient, which is much larger than the in-plane linear CTE measured from a thin film $[11,12]$. The material properties used in the modeling are listed in table 2 [10-19].

\section{Heat tranfer in air}

There are three modes of heat transfer affecting a thermal micro-actuator immersed in air: conduction, convection and radiation. The relative importance of heat transfer modes depends on operating temperatures and dimensions of the device and cavity, in particularly the dimensions of the air gaps next to the released device. Heat conduction in air is relatively important when the air gap distance is small, say several microns. It happens significantly over a conduction layer in close proximity to the hot device. Heat convection plays a role in carrying heat and mass from the conduction layer to the colder ambience at a larger distance away [20]. Micro-scale heat convection in air is not zero [21], but it may be secondary as compared to heat conduction through paths like air or conducting solids. At a low operating temperature (e.g., $<300{ }^{\circ} \mathrm{C}$ ), micro-scale heat transfer by radiation in air is small compared to that by conduction or convection over a wide range of dimensions [22]. Therefore, only heat conduction and convection in air is considered in the present modeling.

Based on the cavity configuration around the actuator, there are two major heat conduction paths in air. The first path is in plane, from the actuator to the top bounds of the cavity, at a distance of about 250-300 $\mu \mathrm{m}\left(g_{x}\right.$ or $\left.g_{y}\right)$; the second path is out-plane, from the actuator to the bottom of the cavity, at a distance of about $450 \mu \mathrm{m}\left(g_{z}\right)$. It is approximated [23] to have a heat conduction coefficient $h_{\text {cond }}$,

$$
h_{\text {cond }}=k_{\text {air }} / \Delta z,
$$

where $k_{\text {air }}$ is the air thermal conductivity of $0.027 \mathrm{~W} \mathrm{~m}^{-1} \mathrm{~K}^{-1}$ [24]. In this case, the effective heat transfer coefficient by air conduction ranges between 60 and $108 \mathrm{~W} \mathrm{~m}^{-2} \mathrm{~K}^{-1}$.

The convective heat transfer coefficient can be estimated from the limiting case for a horizontal cylinder immersed in air. In the limiting case where the horizontal cylinder becomes a very fine wire, the Nusselt number has a finite value of 0.36 for Rayleigh number ranging between $10^{-3}$ and $10^{-6}$ according to Churchill and Chu [25]. The convective heat

Table 2. Material properties used for FE modeling.

\begin{tabular}{llll}
\hline Material properties & Si $[15,16]$ & Al [17-19] & SU-8 [11-14] \\
\hline Young's modulus, $E(\mathrm{GPa})$ & 130 & 69 & 3.2 \\
Poisson's ratio, $v$ & 0.26 & 0.35 & 0.33 \\
Coefficient of thermal expansion $\left(\mathrm{ppm}{ }^{\circ} \mathrm{C}^{-1}\right)$ & 2.6 & 23.1 & 150.7 \\
Thermal conductivity $\left(\mathrm{W} \mathrm{m}^{-1} \mathrm{~K}^{-1}\right)$ & 148 & 237 & 0.2 \\
Electric resistivity $(\Omega \mathrm{m})$ & $2 \times 10^{-2}$ & $3.1 \times 10^{-8}$ & $>1.2 \times 10^{8}$ \\
Temperature coefficient of resistivity $\left({ }^{\circ} \mathrm{C}^{-1}\right)$ & - & $4.1 \times 10^{-3}$ & - \\
\hline
\end{tabular}




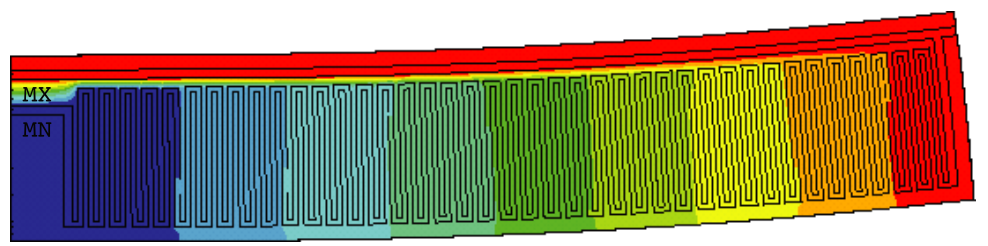

(a) Top electric potential (V)

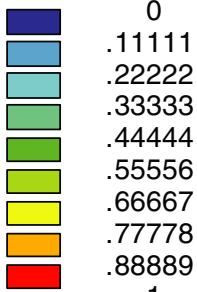

1

(c) Top temperature $\left({ }^{\circ} \mathrm{C}\right)$

Figure 5. Simulated scalar fields on which the layout of silicon microstructure (or the heater lines) are superimposed (at $1 \mathrm{~V}$ driving voltage and an assumed heat transfer coefficient in air of $\left.250 \mathrm{~W} \mathrm{~m}^{-2} \mathrm{~K}^{-1}\right)$ : $(a)$ electric potential on the top; $(b)$ temperature distribution on the side; (c) temperature distribution on the top.

transfer coefficient is hence estimated as

$$
h_{\text {conv }}=0.36 k_{\text {air }} / D \text {, }
$$

where $D$ is the diameter of the horizontal fine wire. An equivalent diameter for the actuator block is defined as $4 A / P$, in which $A$ is the cross sectional area and $P$ is the perimeter over the section. Using the dimensions listed in table 1, the equivalent diameter is calculated as $60.9 \mu \mathrm{m}$. Upon substituting the dimension into equation (2), the convective heat transfer coefficient is estimated to be $159.5 \mathrm{~W} \mathrm{~m}^{-1} \mathrm{~K}^{-1}$.

Summing up the parts of conduction and convection in the air surrounding the actuator, a total heat transfer coefficient $h_{\text {total }}$ is estimated to be

$$
h_{\text {total }}=h_{\text {cond }}+h_{\text {conv }}
$$

which ranges between $219 \mathrm{~W} \mathrm{~m}^{-2} \mathrm{~K}^{-1}$ and $267 \mathrm{~W} \mathrm{~m}^{-2} \mathrm{~K}^{-1}$.

\section{Simulation results}

A typical coupled-field analysis using the above-mentioned 3D finite element model is presented below. The analysis presented in this section uses a potential difference of $1 \mathrm{~V}$, both initial and boundary temperature of $25{ }^{\circ} \mathrm{C}$ (denoted as $\left.T_{0}\right)$, and a total heat transfer coefficient of air $\left(h_{\text {total }}\right)$ of $250 \mathrm{~W} \mathrm{~m}^{-2} \mathrm{~K}^{-1}$.

Figure 5(a) shows the electric potential distribution over the top of the asymmetric actuator. A potential difference is applied across the aluminum heater and induces a current flow along it. The straight segments are shorter than the meandering segment. Therefore, a potential drop primarily takes place over the meandering segment (with reference to figure 2). There is little potential drop along the two straight segments, including the cross beam.

Figures 5(b) and (c) depict the temperature distribution over the side and the top of the composite actuator. It is observed from figure $5(b)$ that the side temperature is almost

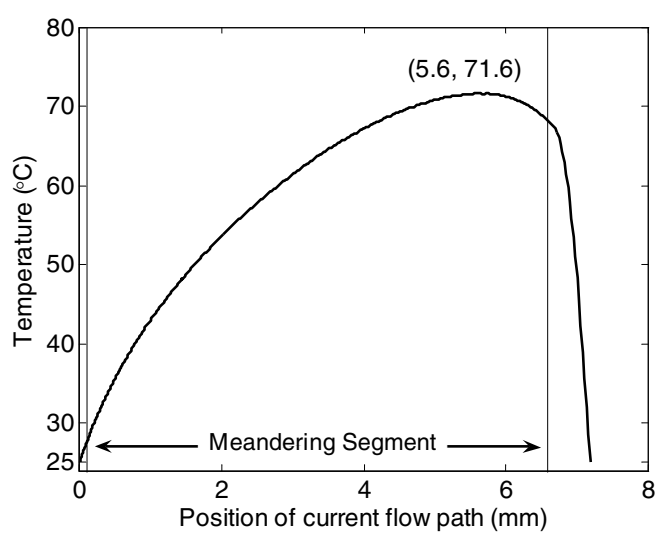

Figure 6. Temperature profile along the current flow path, whose direction and segments are indicated in figure 2 (simulated at $1 \mathrm{~V}$ driving voltage and an assumed heat transfer coefficient in air of $250 \mathrm{~W} \mathrm{~m}^{-2} \mathrm{~K}^{-1}$ ).

uniform across the thickness, though varying along the length. This temperature distribution confirms that heat transfer across the thickness is improved, with little thermal gradient across the thick polymer layer. The top temperature contour in figure $5(c)$ shows that high temperature is developed in the meandering segment. The temperature reaches a maximum of $71.6^{\circ} \mathrm{C}$, as indicated with ' $\mathrm{MX}$ ' in figure $5(c)$ (near the cross beam).

However, the temperature along the long straight beam remains relatively low. The temperature contour at the top (figure $5(c)$ ) shows that the straight beam is at a lower temperature than the meandering neighbor at the same longitudinal distance from the root. This is because it is directly connected to the heat sink at the root and it is shorter in length compared to the meandering region. Moving along the heat flow path on the aluminum film, temperature changes in an asymmetric profile as shown in figure 6 . The temperature 


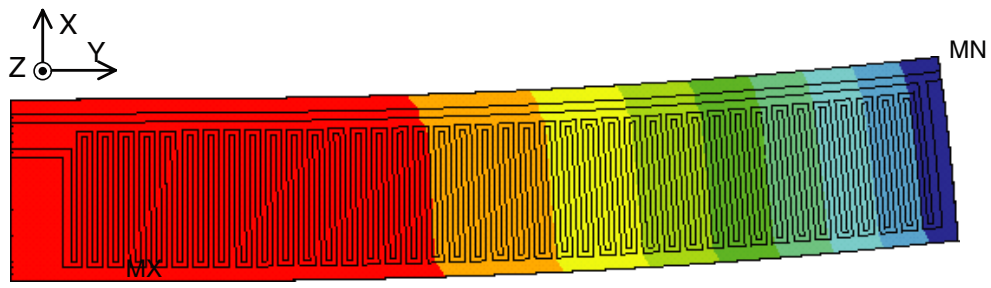

(a) Lateral displacement $U_{\mathrm{X}}(\mu \mathrm{m})$

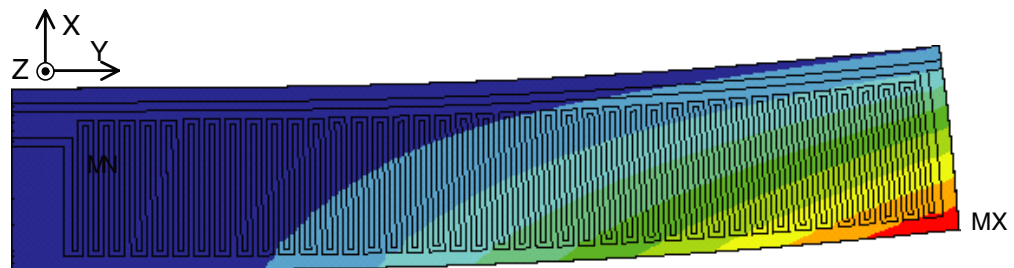

(b) Longitudinal displacement $U_{\mathrm{Y}}(\mu \mathrm{m})$

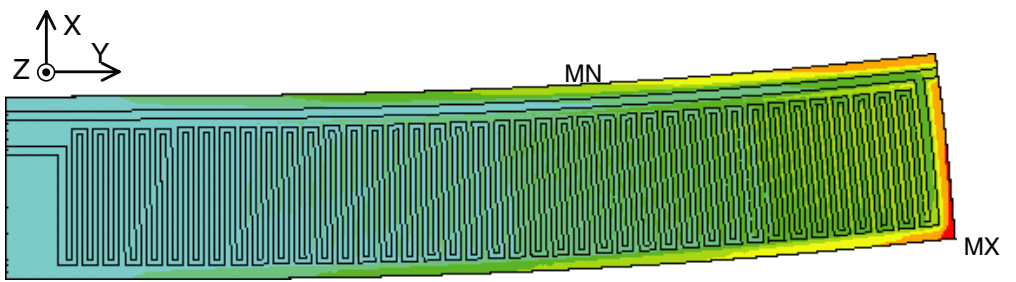

(c) Vertical displacement $U_{Z}(\mu \mathrm{m})$

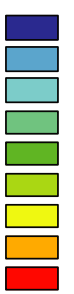

$-5.389$

$-4.789$

$-4.189$

$-3.589$

$-2.989$

$-2.389$

$-1.789$

$-1.189$

$-.58871$

.011354

$-.00585$

.31141

.62867

.94593

1.263

1.58

1.898

2.215

2.532

2.849

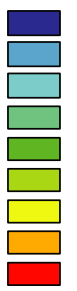

$-06939$

$-.03899$

$-.00859$

.02181

.05222

.08262

.11302

.14342

.17383

.20423

Figure 7. Simulated displacements as viewed from the top (at $1 \mathrm{~V}$ driving voltage and an assumed heat transfer coefficient in air of $\left.250 \mathrm{~W} \mathrm{~m}^{-2} \mathrm{~K}^{-1}\right)$ : (a) lateral displacement field $\left(U_{\mathrm{X}}\right)$; $(b)$ longitudinal displacement field $\left(U_{\mathrm{Y}}\right) ;(c)$ vertical displacement field $\left(U_{\mathrm{Z}}\right)$.

profile has two ends fixed at $25{ }^{\circ} \mathrm{C}$. It rises to a maximum of $71.6{ }^{\circ} \mathrm{C}$ at a relative position of $78 \%$ over the total length of the silicon skeleton. After reaching the maximum, the temperature sharply drops along the straight beam.

Figure 7 depicts the deformed shape and the corresponding displacement fields of the proposed actuator when driven at $1 \mathrm{~V}$. It is observed that the induced displacement is predominantly in plane. The expanded polymer opens the gaps between the silicon microstructures, contributing to longitudinal expansion of the meandering segment. The expanded meandering segment then pushes the long straight beam, resulting in a large lateral displacement as observed at the actuator tip. There is little out-of-plane bulging observed at the free edges of the bonded polymers. Out-of-plane bulging is suppressed by the lateral constraints of the high-aspect-ratio silicon microstructure. The bulging is slightly higher on the front rim of actuator, because the polymer along the rim is only constrained on one side.

Besides the coupled-field analysis at $1 \mathrm{~V}$, displacementfield analyses under three separate concentrated loads were conducted to evaluate the static stiffness at the apex of the actuator (see figure $2(b)$ ). The simulated performance of the actuator is summarized in table 3 . It is observed that the actuator possesses considerable stiffness in all three directions. The transverse and out-plane stiffness is higher than the lateral stiffness, which corresponds to the actuation direction. The lateral actuation force is estimated by multiplying the lateral motion induced at $1 \mathrm{~V}$ and the lateral stiffness. It turns out to be $7.3 \mathrm{mN}$, which is considered high as compared to the
Table 3. Simulated performance at a driving voltage of $1 \mathrm{~V}$ and a total heat transfer coefficient of $250 \mathrm{~W} \mathrm{~m}^{-2} \mathrm{~K}^{-1}$.

\begin{tabular}{ll}
\hline Specifications & Values \\
\hline Driving voltage $(\mathrm{V})$ & 1 \\
Resistance $(\Omega)$ & \\
at $\approx 0 \mathrm{~V}$ & 102.7 \\
at $1 \mathrm{~V}$ & 115.8 \\
Power consumption $(\mathrm{mW})$ at $1 \mathrm{~V}$ & 8.6 \\
Maximum temperature $\left({ }^{\circ} \mathrm{C}\right)$ at $1 \mathrm{~V}$ & 71.6 \\
Average temperature $\left({ }^{\circ} \mathrm{C}\right)$ at $1 \mathrm{~V}$ & 56.9 \\
Displacements at apex $(\mu \mathrm{m})$ at $1 \mathrm{~V}$ & \\
$\quad$ lateral direction, $U_{\mathrm{X}}$ & 5.1 \\
$\quad$ longitudinal or transverse direction, $U_{\mathrm{Y}}$ & 0.5 \\
$\quad$ out-of-plane direction, $U_{\mathrm{Z}}$ & 0.06 \\
Static stiffness at apex $\left(\mathrm{kN} \mathrm{m}{ }^{-1}\right)$ & \\
$\quad$ lateral direction, $k_{\mathrm{x}}$ & 1.2 \\
$\quad$ longitudinal or transverse direction, $k_{\mathrm{y}}$ & 89.3 \\
normal direction, $k_{\mathrm{z}}$ & 4.5 \\
Estimated lateral force $(\mathrm{mN})$ at $1 \mathrm{~V}$ & 6.1 \\
\hline
\end{tabular}

reported electro-thermal actuators made of polysilicon and silicon reported in $[6,26,27]$.

The coupled-field analysis above is performed using a heat transfer coefficient in air at $250 \mathrm{~W} \mathrm{~m}^{-2} \mathrm{~K}^{-1}$. This value is derived from the heat transfer law for the macroscopic scale. However, heat transfer in air at the microscopic scale is not completely understood. A parametric study is performed 


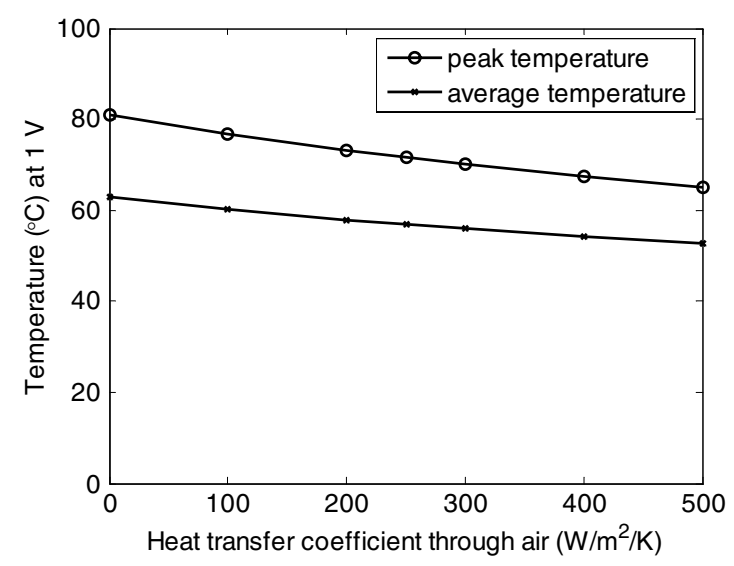

Figure 8. Influences of convection and conduction in air on the actuator's temperature induced at $1 \mathrm{~V}$.

here to investigate the influence of the heat transfer in air on the temperature induced in the present actuator. In this study, the driving voltage is kept at $1 \mathrm{~V}$ but the heat transfer coefficient in air around the actuator is varying from 0 to $500 \mathrm{~W} \mathrm{~m}^{-2} \mathrm{~K}^{-1}$. Figure 8 shows that the temperatures induced by resistive heating at $1 \mathrm{~V}$ decrease with an increase in the heat transfer coefficient in air. The average induced temperature for a model with zero heat transfer in air is $9 \%$ higher than that for a model with a heat transfer coefficient of $250 \mathrm{~W} \mathrm{~m}^{-2} \mathrm{~K}^{-1}$. The difference in the average induced temperature increases if heat transfer in air increases. Based on the parametric analysis above, the induced temperatures are found to be dependent on heat transfer coefficients in air but do not change drastically over the simulated range. This suggests that heat dissipation of the present actuator is mainly by conduction through the silicon microstructure and the polymer encapsulant to the heat sink at the root.

\section{Fabrication}

The device is fabricated using bulk micromachining of silicon and SU-8-2002 polymer filling. A sputtered aluminum film is deposited on the top of a 4 inch silicon wafer. It is then patterned using a resist mask. The resist mask is kept and used again for a later etching process. Deep reactive ion etching (DRIE) of the silicon substrate forms cavities and trenches that define the shape of the silicon microstructure, as shown in figure $9(a)$. Afterwards, a negative photo-resist of SU-8-2002 is cast and patterned to encase the silicon structures, as shown in figure $9(b)$. Finally, the actuator structures are released from the underlying substrate by backside etching using a nitride mask. Details of the fabrication process are reported in an accompanying paper with a focus on fabrication technology [28].

\section{Characterization}

A micro-actuator device is tested on a probe station, using a microscope and a network analyzer. An electric potential difference is applied to contact pads of the device under test using two probes. The induced current is measured using the network analyzer. The consumed power and the temperature rise are then derived from the measured voltage and current. Deflection of the activated device is measured in pixels using digital images, which are captured by a digital camera mounted on the microscope. Dimensions of the image pixels are measured using a reference scale of the meandering pattern, which comprises equal silicon thickness and gap spacing of $3 \mu \mathrm{m}$.

Figure 10(a) shows that the current flow through the aluminum heater is not linear with the voltage. It increases at a decreasing rate with the voltage. This implies electric resistance increases with the voltage, as a result of resistive heating. The induced temperature rises due to resistive heating can be estimated from the change in resistance using the reported temperature coefficient of resistivity (TCR) for the aluminum film [19], as given in table 1. The derived temperature represents an average temperature rise over the heater. Figure $10(b)$ shows that it increases in a quadratic trend with the driving voltage.

The measured deflection is obtained by comparing the images before and after the electrical activation. For example, figure 11 shows an image of an inactive actuator and an image of the actuator activated at $1.75 \mathrm{~V}$. In the optical images, the SU-8 polymer is hardly visible due to its transparency; whereas the aluminum heater is clearly seen. It is observed that the activated composite actuator bends leftwards (the direction towards the long straight beam). As shown in figure 10(c), the measured apex displacement increases with respect to the driving voltage. The trend of displacement increment is almost quadratic, like the trend of the average temperature rise.

The asymmetric composite actuator achieves a $25 \mu \mathrm{m}$ maximum lateral displacement at $1.75 \mathrm{~V}$ driving voltage and at $17.8 \mathrm{~mW}$ input power. The lateral blocked force is estimated to be $30 \mathrm{mN}$ by multiplying the measured displacement at $1.75 \mathrm{~V}$ with the simulated stiffness. In addition, it is estimated that the large motion at $1.75 \mathrm{~V}$ is induced at an average temperature rise of $196{ }^{\circ} \mathrm{C}$. The performance of the present actuator design in comparison with the previous in-plane thermal actuators of comparable dimensions [6, 26, 27] is listed in table 4 . The comparison table shows that the newly designed composite actuator produces a high actuation force and a high displacement at a low operating temperature and a low driving voltage and power.

After the driving voltage is released, the inactive actuator cools down and returns to its original position. Voltages higher than $2 \mathrm{~V}$ are to be avoided for this sample device because they are expected to heat up the actuator beyond $200{ }^{\circ} \mathrm{C}$, which is close to the reported glass transition temperature for SU-8 around $220{ }^{\circ} \mathrm{C}$ [11]. When heated beyond the glass transition temperature, $\mathrm{SU}-8$ polymer is prone to irreversible shrinkage [11], which induces a prestress to bend the original position of the inactive composite actuator. The shrinkage-induced bending is opposite to the normal actuation direction. It is permanent, but unintended for repeatable operation of the actuator.

The measured responses are compared with the simulated results obtained from the numerical model above. The simulation predicts similar trends of electric current, temperature and apex displacements, with respect to the driving voltage (see figure 10). The simulated results 


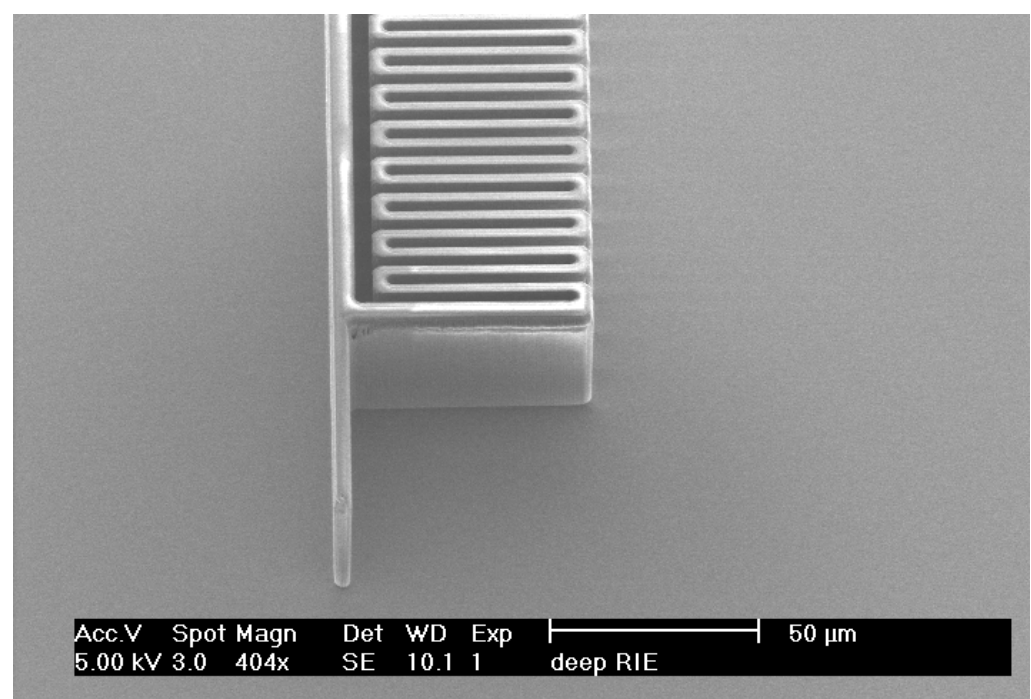

(a)

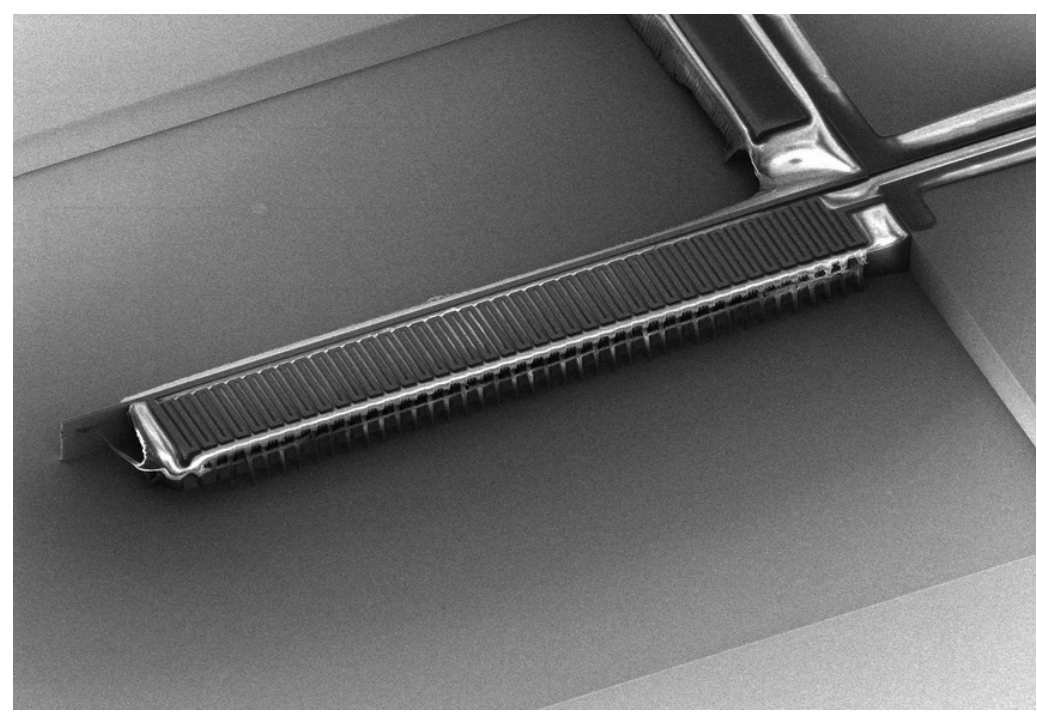

(b)

Figure 9. Scanning electron micrographs of devices: (a) silicon microstructure after deep reactive ion etching (DRIE); (b) SU-8 encasing the silicon microstructure.

Table 4. Benchmarking.

\begin{tabular}{llll}
\hline Specifications & Reference [6] & Reference [27] & Present \\
\hline Design layout & $\mathrm{U}$ shape & $\mathrm{V}$ shape & Asymmetric meandering \\
Composition materials & PolySi & $\mathrm{Si}$ & $\mathrm{Si} /$ SU-8/Al \\
Actuator length $(\mu \mathrm{m})$ & $500-750$ & 1000 & 530 \\
Actuator width $(\mu \mathrm{m})$ & $\sim 10$ & $\sim 200$ & $\sim 90$ \\
Actuator height $(\mu \mathrm{m})$ & $2-3$ & 50 & 50 \\
Number of flexures per actuator array & 1 & 10 & 1 \\
Flexure width $(\mu \mathrm{m})$ & $1-3$ & 10 & $3-5$ \\
Driving voltage $(\mathrm{V})$ & 10 & 12 & 1.75 \\
Power consumption per actuator array $(\mathrm{mW})$ & 20 & 840 & 18 \\
Operating temperature $\left({ }^{\circ} \mathrm{C}\right)$ & $<600$ & $<527$ & $<200$ \\
Actuation displacement $(\mu \mathrm{m})$ & 20 & $12-20$ & 25 \\
Blocked actuation force $(\mathrm{mN})$ & 0.003 & 6.7 & 30 \\
\hline
\end{tabular}

agree well with the measurement data over a low voltage range where resistive heating is not too high. In the low voltage range $(<1 \mathrm{~V})$, a slight discrepancy is observed: the simulated average temperature is slightly lower than the value estimated from the assumed TCR and the observed change in resistance, even though the simulated displacement agrees very well 


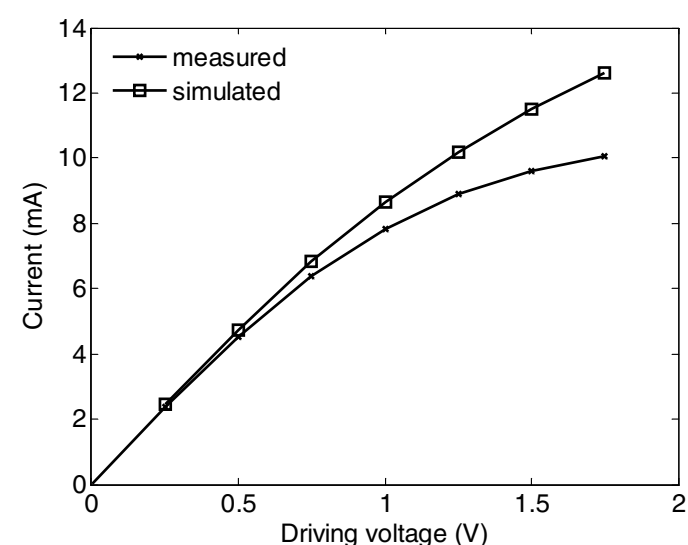

(a)

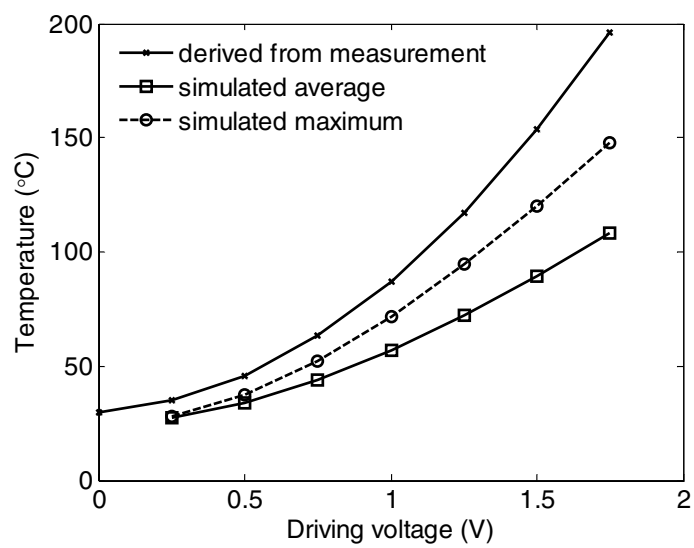

(b)

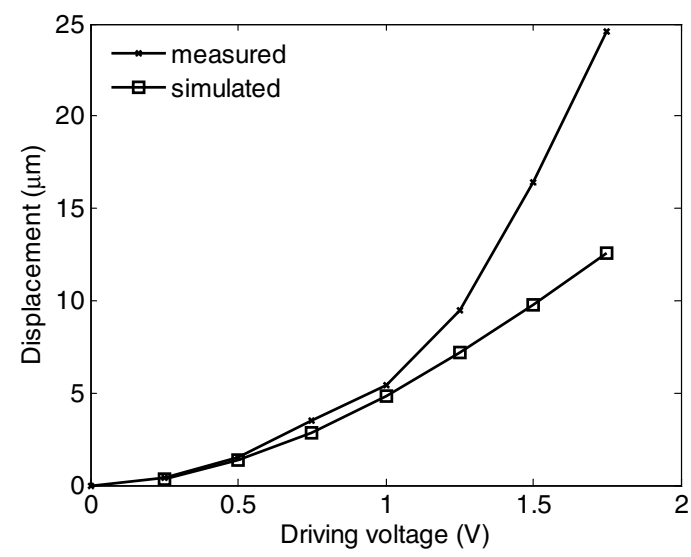

(c)

Figure 10. Measurement data and simulation results with respect to the driving voltage (at an assumed heat transfer coefficient in air of $250 \mathrm{~W} \mathrm{~m}^{-2} \mathrm{~K}^{-1}$ ): (a) current; $(b)$ average and maximum temperature; $(c)$ lateral displacement.

with that measured. This observation implies either that the polymeric CTE put into the numerical model is probably higher than the true property, or that the input thermo-physical properties for thermal simulation do not well represent the true properties of the device under test. In the high voltage range $(>1 \mathrm{~V})$, the simulation underestimates the temperature rise and the induced deflection, but overestimates the induced current. This discrepancy may be attributed to decreasing thermal conductivity of silicon or nonlinear properties of SU-8 polymer over the range of elevated temperatures.

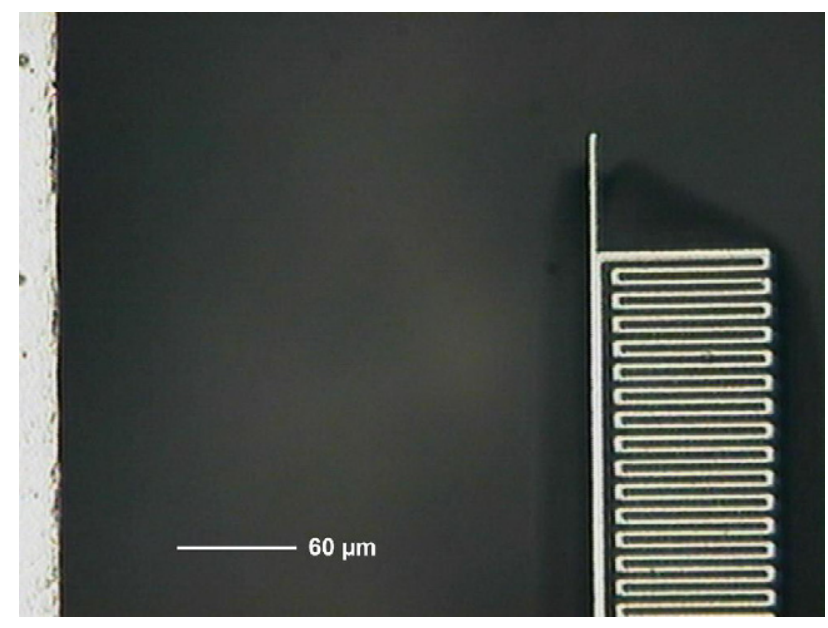

(a)

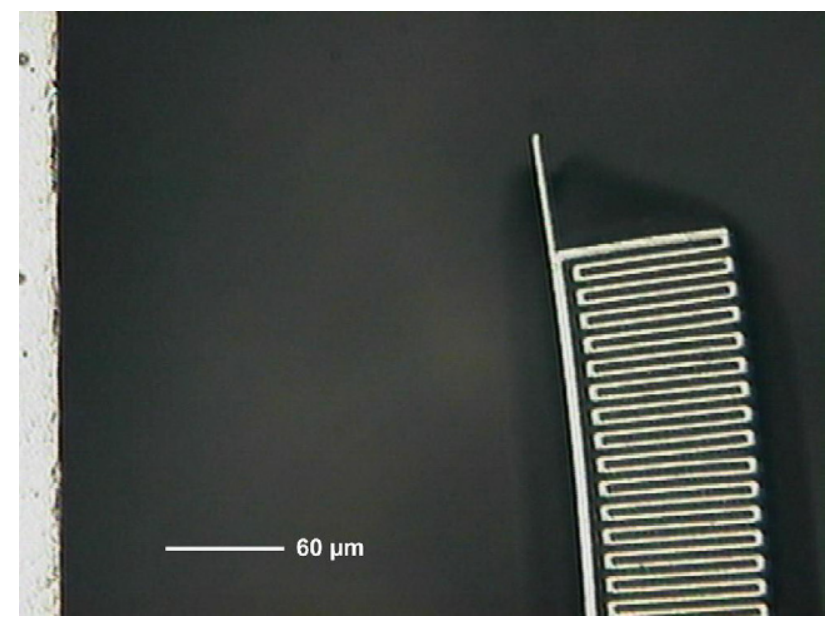

(b)

Figure 11. Optical images of a sample asymmetric actuator, showing a region neighboring its tip: (a) an inactive composite unimorph; (b) an activated composite unimorph at $1.75 \mathrm{~V}$.

\section{Conclusions}

We have presented the design, simulation and characterization of a new type of in-plane thermal actuator, which incorporates silicon/SU-8 polymeric composite. The new thermal actuator acts as a unimorph, producing in-plane bending motion when electro-thermally activated. The fabricated in-plane thermal unimorph provides excellent actuation performance: a large displacement and a high stiffness at low power consumption and a low driving voltage $(<1 \mathrm{~V})$. A $530 \mu \mathrm{m}$ long, $90 \mu \mathrm{m}$ wide and $50 \mu \mathrm{m}$ thick device demonstrates a maximum lateral displacement of $25 \mu \mathrm{m}$ at $1.75 \mathrm{~V}$ driving voltage and at 17.8 $\mathrm{mW}$ input power, at an estimated average temperature below $200{ }^{\circ} \mathrm{C}$.

Since its polymeric component is constrained and reinforced by a high-aspect-ratio silicon microstructure, the composite actuator possesses relatively high stiffness in the actuation direction. It is simulated to have a lateral stiffness of $1.2 \mathrm{kN} \mathrm{m}^{-1}$. At $1.75 \mathrm{~V}$ driving voltage, the actuator is estimated to produce a $30 \mathrm{mN}$ blocked lateral force, which is high compared to other reported micro-actuators. 
In conclusion, a versatile and power efficient electrothermal unimorph actuator using polymeric composite is successfully demonstrated. With the improved actuation capability, the electro-thermally-activated polymeric composite unimorph can potentially be considered for a wider range of applications where energy consumption is a concern.

In this study, a preliminary numerical model is developed based on the temperature-independent properties (except the resistivity with linear temperature dependence). It provides reliable prediction for actuator performance in a low voltage range $(<1 \mathrm{~V})$. The prediction, however, deviates from the measurement in a high voltage range $(>1 \mathrm{~V})$, where the actuator is subjected to elevated temperature. In view of this, the model is to be refined with accurate inputs for temperaturedependent properties. Refined modeling of the polymeric composite actuator is now in progress.

\section{Acknowledgments}

The authors are grateful to the Delft Center of Mechatronics and Microsystems (DCMM) for research funding and the DIMES-ICP group for their support in device fabrication. In addition, the first author would like to acknowledge Dr K M B Jansen, Dr M Langelaar and Mr J Wei for their stimulating discussions and assistance.

\section{References}

[1] Riethmueller W and Benecke W 1988 Thermally excited silicon microactuators IEEE Trans. Electron. Devices 35 758-63

[2] Ataka M, Omodaka A, Takeshima N and Fujita H 1993 Fabrication and operation of polyimide bimorph actuators for aciliary motion system J. Microelectromech. Syst. 2 146-50

[3] Sehr H, Evans A G R, Brunnschweiler A, Ensell G J and Niblock T E G 2001 Fabrication and test of thermal vertical bimorph actuators for movement in the wafer plane J. Micromech. Microeng 11 306-10

[4] Guckel H, Klein J, Christenson T, Skrobis K, Landon M and Lovell E G 1992 Thermo-magnetic metal flexure actuators Technical Digest, IEEE Solid State Sensor and Actuator Workshop (Hilton Head Island, SC) pp 73-5

[5] Comtois J H and Bright V M 1997 Applications for surface-micromachined polysilicon thermal actuators and arrays Sensors Actuators A 58 19-25

[6] Pan C S and Hsu W 1997 An electro-thermally and laterally driven polysilicon microactuator J. Micromech. Microeng. 7 7-13

[7] Nguyen N T, Ho S S and Low C L N 2004 A polymeric microgripper with integrated thermal actuators J. Micromech. Microeng. 14 969-74

[8] Chronis N and Lee L P 2005 Electrothermally activated SU-8 microgripper for single cell manipulation in solution J. Microelectromech. Syst. 14 857-63
[9] Lau G K, Goosen J F L, van Keulen F, French P J and Sarro P M 2006 Actuated elastomers with rigid vertical electrodes J. Micromech. Microeng. 16 S35-S44

[10] Huang Q A and Lee N K S 1999 Analysis and design of polysilicon thermal flexure actuator J. Micromech. Microeng. 9 64-70

[11] Feng R and Farris R J 2002 The characterization of thermal and elastic constant for an epoxy photoresist SU-8 coating J. Mater. Sci. 27 4793-9

[12] Feng R and Farris R J 2003 Influence of processing conditions on the thermal and mechanical properties of SU-8 negative photoresist coatings J. Micromech. Microeng. 13 80-8

[13] Li H, Jacob K I and Wong C P 2003 An improvement of thermal conductivity of underfill materials for flip-chip packages IEEE Trans. Adv. Packag. 26 25-31

[14] Hexion 2005 Technical Data Sheet: EPON Resin 8021, SC: 1525-01, Hexion Specialty Chemicals, Inc., USA

[15] Wortman J J and Evans R A 1965 Young's modulus, shear modulus, and Poisson's ratio in silicon and germanium J. Appl. Phys. 36 153-6

[16] Berger L I 2006 Properties of semiconductors CRC Handbook of Chemistry and Physics 87th edn ed D R Lide (Boca Raton, FL: Taylor and Francis) (internet version)

[17] Frederikse H P R 2006 Elastic constants of single crystals CRC Handbook of Chemistry and Physics 87th edn ed D R Lide (Boca Raton, FL: Taylor and Francis) (internet version)

[18] Frederikse H P R 2006 Thermal conductivity of metals and semiconductors as a function of temperature $C R C$ Handbook of Chemistry and Physics 87 th edn ed D R Lide (Boca Raton, FL: Taylor and Francis) (internet version)

[19] Aviles F, Ceh O and Oliva A I 2005 Physical properties of Au and $\mathrm{Al}$ thin films measured by resistive heating Surf. Rev. Lett. 12 101-6

[20] Mahony J J 1957 Heat transfer at small Grashof numbers Proc. R. Soc. A 238 412-23

[21] Leung A M, Jones J, Czyzewska E, Chen J and Pascal M 1997 Micromachined accelerometer with no proof mass Technical Digest for International Electron Devices Meeting (7-10 December 1997) pp 899-902

[22] Liang X G and Guo Z Y 2006 The scaling effect on the thermal processes at mini/microscale Heat Transf. Eng. 27 30-40

[23] Hickey R, Sameoto D, Hubbard T and Kujath M 2003 Time and frequency response of two-arm micromachined thermal actuators J. Micromech. Microeng. 13 40-6

[24] Incropera F P and DeWitt D P 1996 Chapter 9: Free convection Fundamentals of Heat and Mass Transfer 4th edn (New York: Wiley) pp 485-518

[25] Churchill S W and Chu H H S 1975 Correlating equations for laminar and turbulent free convection from a horizontal cylinder Int. J. Heat Mass Transf. 18 1049-53

[26] Bell D J, Lu T J, Fleck N A and Spearing S M 2005 MEMS actuators and sensors: observations on their performance and selection for purpose J. Micromech. Microeng. 15 S153-S164

[27] Maloney J M, Schreiber D S and DeVoe D L 2004 Large-force electrothermal linear micromotors J. Micromech. Microeng. 14 226-34

[28] Chu Duc T, Lau G K, Wei J and Sarro P M 2006 Silicon-polymer laterally stacked bimorph micro-gripper Technical Digest for the 17th Micromechanics Europe (3-5 September 2000) pp 197-200 